Goldschmidt 2021 Abstract

https://doi.org/10.7185/gold2021.6679

\section{Clumped isotope thermometry in earthworm carbonates}

\author{
${ }^{1}$ INDIAN INSTITUTE OF SCIENCES \\ ${ }^{2}$ Indian Institute of Science \\ ${ }^{3}$ Rotterdam University of Applied Science \\ ${ }^{4}$ University of Reading \\ ${ }^{5}$ University of York \\ Presenting Author:pghosh@iisc.ac.in
}

SANCHITA BANERJEE ${ }^{1}$, PROSENJIT GHOSH ${ }^{2}$ THAMIZHARASAN $S^{2}$, EMMA VERSTEEGH ${ }^{3}$, STUART BLACK $^{4}$ AND MARK HODSON ${ }^{5}$

Clumped isotope thermometry in earthworm carbonates Sanchita Banerjee ${ }^{1}$, Prosenjit Ghosh ${ }^{1}$, Thamizhararan S. ${ }^{1}$, Emma A.A. Versteegh ${ }^{2}$, Stuart Black ${ }^{3}$, Mark E. Hodson ${ }^{4}$.

\section{${ }^{1}$ Indian Institute of Science, Bangalore, India;}

${ }^{2}$ Rotterdam University of Applied Science, Netherlands; ${ }^{3}$ University of Reading, Whiteknights, UK; ${ }^{4}$ University of York, Heslington, UK.

Earthworm-secreted calcium carbonate can store carbon derived from the soil-atmosphere interface on geological timescales [1]. The mechanism of calcification $[2,3,4]$ is well understood based on multiple years of research conducted both under controlled and natural conditions. We analysed carbonate granules produced by the earthworm Lumbricus terrestris cultured in variable $\mathrm{pH}$ and temperature for $\delta^{18} \mathrm{O}$ to establish thermometry [2]. The governing equation proposed for the thermometry differed from the inorganic calcite precipitation relationship, capturing the signature of kinetic processes during carbonate growth. We have now analysed the granules for clumped isotope thermometry.

This provides an opportunity to understand the role of kinetic processes in governing the relationship of clumped isotope in the carbonate system. The clumped isotopic composition of these carbonates yields the following relationship with varying temperature:

The linear regression relationship obtained in this study has a similar slope as seen in case of inorganic calcite [5] and otolith carbonate [6]. However, the intercept of the governing equation varied significantly denoting carbonate growth rate. The study presented here provides the first experimental results of clumped isotope composition on carbonates precipitated under monitored disequilibrium conditions and thus, enables quantification of growth rate dependency on clumping. The intercept of the linear regression relationship differs from the line proposed for inorganic calcite precipitation and thus introduces a new parameter to quantify the kinetic process. In this study replicate experiments were performed on carbonate granules generated at controlled temperature and with a knowledge of water isotopic composition.

Refs: [1] Lambkin et al., 2011, Pedobiologia 54S; [2]
70; [4] Gago-Duport et al., 2008, JSB 162; [5] Ghosh et al., 2006, GCA 70; [6] Ghosh et al., 2007, GCA 71. 